\title{
How wort boiling process affects flavonoid polyphenols in beer
}

\author{
Alexandr Mikyška*, Martin Dušek \\ Research Institute of Brewing and Malting, \\ Lípová 511/15, CZ 12000 Praha 2
}

*correspondence e-mail: mikyska@beerresearch.cz

\begin{abstract}
Beer and brewing raw materials are a source of number of polyphenol substances with potential or proven beneficial biological effects. In pilot brews of Czech pale lager (200 I) the behavior of hop-derived polyphenol substances during wort boiling process in various hopping regimes was studied. Prenylflavonoids, flavonoids and their O-glycosides were determined by liquid chromatography coupled to high resolution mass spectrometry (LC-HR/MS) with sample preparation by the QuEChERS method. The concentration of flavanols (catechin, epicatechin) in hopped wort and beer is dominated by hop raw material, when hopping with aromatic hops rich in polyphenols, $2 / 3$ of the amount in beer is affected by hops. In contrast, the concentration of their mono-O-glucosides in beer does not depend on hopping. Flavonols quercetin, kaempferol and multifidol are found in wort and beer mainly in glycosidic form. The source of all these substances in beer is ex-clusively hops. Conversely, malt is the only source of myricetin and myricetin-O-glucoside in beer. Main part of hop-derived flavonoids is released during wort boiling into wort within 15-30 minutes. Splitting the hop dose or low pressure boiling technology had no significant effect on health-promoting polyphenols. Beer hopped with hops rich in flavonoids contains a relatively high amount of health-promoting polyphenols, while beer hopped with hop extract is very poor in these antioxidants.
\end{abstract}

Key words: polyphenols, flavonoids, flavonoid-O-glycosides, prenylflavonoids, wort boiling, hops, beer

\section{Introduction}

Polyphenol substances can influence beer quality, its colloidal and sensory stability. It is a very diversified group of substances, whose individual components differ greatly in their chemical structure and therefore have different properties in terms of antiradical capabilities and other bio-logical functions. Some simple and complex polyphenols and their oxidation products are sensory active, affecting the bitterness and astringency of beer (Callemien et al., 2005; McLaughlin et al., 2008). Both hops and malt contain phenolic monocarboxylic acids and flavonoids (Wannenmacher et al., 2018), brewing raw materials are a source of polyphenol compounds with antioxidant and antiradical properties (free radical scavengers), ie with potential or proven biological effects. A number of re- views summarize the current state of knowledge of the biological effects of hop sub-stances (Zanoli et al., 2008; Biendl 2009; Karabin et al., 2016; Bocquet et al., 2018).

A special group of substances are hop prenylflavonoids with a spectrum of antioxidant, anticancerogenic, estrogenic, antimicrobial and other beneficial effects. Prenylflavonoids are chemically related to both polyphenols and bitter hop acids (Stevens et al. 1998), which are also biologically active. Xanthohumol and isoxanthohumol, 6- and 8-prenylnaringenin are the antican-cerogens being investigated and discussed, 6- and 8-prenylnaringenin are probably the most potent phytoestrogens. Hops are the source of prenylflavonoids, xanthohumol, isoxanthohumol and 8-prenylnaringenin (8-PN) in beer. 
Many of their bioactive effects have been demonstrated, in par-ticular, xanthohumol is an inhibitory actor on certain types of cancerous growth, antimicrobial, anti-inflammatory and antioxidant effects (Stevens and Page, 2004, Karabín et al., 2016; Bocquet et al., 2018). Xanthohumol, together with some hop resin components, also acts to inhibit osteopo-rosis (Tobe et al., 1997) and also has significant antimicrobial effects against some significant pathogenic bacteria (Cermak et al, 2015; Cermak et al, 2017; Bogdanova et al, 2018).

The bioactive effects of isoxanthohumol are similar to those of xanthohumol but weaker (Kondo, 2003). The lower efficiency is to some extent compensated by higher concentrations and easy availability in beer. 8-Prenylnaringenin has been identified as the causative agent of the strong estrogenic effects of hops (Milligan et al., 1999). Comparing the estrogenic effects of 8-PN with other clover or soybean substances, it has been shown to be the most effective phytoestrogen known to date. The direct source of 8-PN in beer is the isomerization of desmethylxanthohumol (DMX), which is present in the hops in an amount of 0.10 to $0.40 \mathrm{wt} \%$. (Rong et al., 2000). In con-ventional beers, 8-PN concentrations are very low $(<50 \mu \mathrm{g} / \mathrm{L})$, which are considered physiologi-cally negligible (Krofta, 2008). However, it has been found that bacteria of the intestinal tract are able to transform the isoxanthohumol present in beer to 8-PN. Daily intake of phytoestrogen by regular consumption of beer can thus rise to physiologically active levels (Possemiers et al., 2005, 2006).

During the hopping process, hop prenylflavonoids are partially extracted from the matrix and reacted to form other compounds. Prenylflavonoids undergo isomerization reactions, xantho-humol produces isoxanthohumol, desmethylxanthohumol produces 8-prenylnaringenin. During wort cooling, fermentation and maturation, filtration and stabilization, significant losses occur (Stevens et al., 1999; Mikyška et al., 2019) by sorption to break, yeast, filter materials and other mechanisms.

Proanthocyanidins, also known as condensed tannins, are flavan-3-ol oligomers and pol-ymers that provide anthocyanidins after acid depolymerization. Proanthocyanidins are found in plants where they have different physiological and defense functions. The association of these compounds with organoleptic properties, antioxidant properties and thus potential health benefits has been demonstrated (Callemien et al., 2005a; Maata-Riihinen et al., 2005; Zhou et al., 2005; Dvořáková et al. ., 2008). Both malt and hops contain flavan-3-ol mono-mers and glycosides of these substances (Dvořáková et al., 2008; Olšovská et al., 2013; Kavalier et al., 2011).
Flavonols, especially quercetin and myricetin as well as their glycosides, for example rutin (quercetin $O$-rutinoside) are considered important plant polyphenol antioxidants, rutin is a part of drugs and food supplements, more recently quercetin is promoted in food supplements. Flavonols and their glycosides are part of hop polyphenols (Kavalier et al., 2011) and probably have the strongest antioxidant effects of the flavonoid polyphenols (Nowak et al., 2014).

Important structural determinants of polyphenol antioxidant activity are the $\mathrm{OH}$ groups at the $\mathrm{C} 4$ 'and C3' ( $O$-dihydroxy) positions bound to ring B (flavanols catechin and epicatechin, fla-vonol quercetin) and the 4-oxo group on ring $\mathrm{C}$, especially in combination with a double bond be-tween C2 and C3 (flavonol quercetin) (Nowak et al., 2014). Flavanols and flavonols with OH groups at C4 'and C3' on ring B show chelating properties. They are capable of binding iron and copper transition metal ions that catalyze a series of radical reactions leading to the formation of old-taste carbonyl in beer or oxidative stress at the cellular level (Biendl, 2009; Karabín et al., 2016).

The often controversial findings about the importance of polyphenols in beer were sum-marized by Derdelinckx (2008), most recently by Wannenmacher et al. (2018). The content of polyphenol substances and their transformation products with health benefits in beer strongly de-pends on both raw materials (variety, origin) and technological process. Among other things, Czech beers differ from foreign beers in higher levels of polyphenols. It is listed as one of the characteristics of Czech beer (concentration of total polyphenols in the lager 130-230 mg/L) (Commision, 2008), which distinguishes it from foreign ones (Olšovská et al., 2013).

The generally accepted aims of the wort boiling are the utilization of hop products, i.e. res-ins and essential oils contained therein, sufficient removal of sensory undesirable volatiles, crea-tion of preconditions for good filterability and stability of beer clarity by precipitation of polyphe-nol-protein complexes (Esslinger, 2009; Basarova et al., 2010). These requirements are partly con-tradictory, so it is necessary to make deliberate compromises leading to optimal overall wort quali-ty.

Wort boiling is the most energy-intensive technological operation of the brewing process (Esslinger, 2009). Therefore, ways to save by shortening the operation are sought, for example by using pre-isomerized hop raw materials or by developing more economical boiling systems with limited evaporation. The result of the development are systems of the brewing plant working with non-atmospheric pressure (Hertel and Dillenburger, 2009). Energy savings are also achieved by the production of high-percentage worts with a lower concentration of the original extract in the final beer. 
The aim of our study was focused on elucidation the behavior of hop derived polyphenol compounds with potential health benefit in different hopping regimes of the wort boiling process.

\section{Material and methods}

Pale lager brews were carried out at the RIBM pilot brewery on a multifunctional pilot brewhouse with a nominal batch volume of 150 to $300 \mathrm{~L}$ (Kaspar Schulz, Germany). The worts of all-malt brews were made using a two-mash process from commercial malt of the Bojos variety. The brews were lautered and sparged to an equal final volume of wort. The lag time in the lauter tun lasted $20 \mathrm{~min}$ utes before lautering.

Atmospheric wort boiling (ATM) and two basic boiling systems at elevated pressure - con-stant low pressure boiling (TWB) and dynamic low pressure boiling with variable pressure value (TDWB) were tested. Hop raw materials were combined in atmospheric pressure experimental brews. It was hopped with pellets type 90 of Saaz variety (PE) and $\mathrm{CO}_{2}$ hop extract of Magnum variety (EX) and combination of both in the ratio 1:1 (EX $+\mathrm{PE}$ ). The extract was added at the start of boiling, the pellets after 30 minutes (30\% of the total hopping dose) and 70 minutes ( $20 \%$ of the hopping dose).

The residence time in the whirlpool was 20 minutes, then the wort was cooled with a plate cooler to a fermentation temperature of $10{ }^{\circ} \mathrm{C}$ and aerated to a dissolved oxygen content of $8+/-0.5 \mathrm{mg} / \mathrm{L}$.

The primary fermentation was performed using cylindrical-conical tanks with pitching yeast strain No. 95 of the RIBM Collection. The maximum temperature was $12{ }^{\circ} \mathrm{C}$. After the dif-ference between apparent and final attenuation of about $10 \%$ was reached, the CKT content was cooled to $5-6{ }^{\circ} \mathrm{C}$ within 24 hours and pumped into lager tank. The secondary fermenta-tion/maturation period was three weeks at a temperature of $1-2{ }^{\circ} \mathrm{C}$.

The beers were filtered with a plate filter (Hobra Školník, Czech Republic) and bottled on a double-evacuated machine filler with carbon dioxide pre-filling (Linnea-Zevos, Czech Republic). The bottled beer was pasteurized in the immersion pasteurizer to a level of about 20 PU. Carbon dioxide was used in all beer handling during filtration and bottling.

Common analyzes of worts, hopped worts, beers and total polyphenols were performed ac-cording to EBC Analytical methods (Analytica-EBC, 2010), anthocyanogens and reducing capaci-ty (2,6-dichlorophenol indophenol; DCPI) were determined by MEBAK analytical methods (2013) The antioxidant activity using the stable free rad- ical DPPH (1,1-dipyridyl-2-picryl hydrazyl; DPPH) was determined by a method developed previously (Mikyška et al., 2006).

Flavonoids and their glycosides i sweet wort, hopped wort and beer were determined by liquid chromatography coupled to high resolution mass spectrometry (LCHR/MS) on a Q-Exactive instrument (Thermo Fisher Scientific, Bremen, Germany). The QuEChERS method (Anastassiades et al., 2003) was used to prepare beer samples. The extraction, separation, and detec-tion conditions are described in detail in our previous publication (Mikyška et al, 2019).

The content of individual flavonoids in beer samples was quantified using an external cali-bration curve constructed in the range of 10 to $200 \mu \mathrm{l} / \mathrm{L}$ for all analytes of interest. Quantified were: flavanols (catechin, epicatechin, catechin-O-glucoside, epicatechin- $O$-glucoside), flavonols (myricetin, quercetin, kaempferol, rutin, quercetin-3O-glucoside (1), quercetin- $O$-glucoside (2), kaempferol- $O$-glucoside, myricetin- $O$-glucoside, multifidol-O-glucoside, quercetin- $O$-malonylglucoside) and prenylflavonoids (isoxanthohumol, xanthohumol, 8-prenylnaringenin, 6-prenylnaringenin)

\section{Results and discussion}

Changes in polyphenol concentrations and changes in antioxidant activity values were monitored during the wort boiling from wort to the end of boiling and further in cold wort before fermentation, and in the final beer. Due to changes in extract concentration during boiling, all data were converted to wort with $11 \%$ extract content for comparison of the results.

\section{Total polyphenols, anthocyanogens, antioxidant properties}

The results (Table 1) showed that the substances determined in sum as total polyphenols are released quickly from the hop product into the wort and the increase of its concentration is deter-mined by the content in the hops. Within 15 minutes after the addition of the pellets, the concen-tration of total polyphenols was $85-90 \%$ of their value in the cold hopped wort. Hopping with pol-yphenol-free hop extract resulted in a zero increase of total polyphenols in hopped wort, hopping with Saaz hop pellets resulted at about twice the concentration compare to sweet wort and splitting the dose of 50:50\% hop extract and pellets in about half the increase in comparison with $100 \%$ pellet dose. From the point of view of total polyphe- 
Table 1 Evolution of the total polyphenols and anthocyanogens concentration, antioxidant activity and reducing capacity value during the wort boiling and into the finished beer

\begin{tabular}{|c|c|c|c|c|c|c|c|}
\hline & $0 \mathrm{~min}$ & $30 \mathrm{~min}$ & $60 \mathrm{~min}$ & $75 \mathrm{~min}$ & $90 \mathrm{~min}$ & CW & $\mathrm{BE}$ \\
\hline & \multicolumn{7}{|c|}{ Total polyphenols } \\
\hline PE-ATM & 137 & 233 & 229 & 236 & 234 & 253 & 175 \\
\hline EX-ATM & 152 & 152 & 151 & 151 & 155 & 143 & 106 \\
\hline EX+PE-ATM & 152 & 153 & 187 & 180 & 187 & 195 & 138 \\
\hline PE-TWB & 139 & 212 & 232 & 234 & & 246 & 174 \\
\hline \multirow{2}{*}{ PE-TDWB } & 160 & 225 & 231 & 225 & & 250 & 171 \\
\hline & \multicolumn{7}{|c|}{ Anthocyanogens } \\
\hline PE-ATM & 43 & 69 & 69 & 66 & 65 & 61 & 30 \\
\hline EX-ATM & 42 & 43 & 37 & 37 & 39 & 29 & 19 \\
\hline EX+PE-ATM & 43 & 40 & 44 & 42 & 46 & 41 & 25 \\
\hline PE-TWB & 42 & 56 & 60 & 60 & & 61 & 42 \\
\hline \multirow[t]{2}{*}{ PE-TDWB } & 44 & 58 & 57 & 56 & & 57 & 44 \\
\hline & \multicolumn{7}{|c|}{ Antioxidant activity DPPH } \\
\hline PE-ATM & 56 & 69 & 65 & 70 & 72 & 86 & 52 \\
\hline EX-ATM & 57 & 57 & 57 & 58 & 60 & 63 & 53 \\
\hline EX+PE-ATM & 60 & 61 & 67 & 69 & 70 & 74 & 51 \\
\hline PE-TWB & 59 & 74 & 76 & 80 & & 77 & 41 \\
\hline \multirow[t]{2}{*}{ PE-TDWB } & 62 & 74 & 77 & 81 & & 82 & 56 \\
\hline & \multicolumn{7}{|c|}{ Reducing capacity DCPI } \\
\hline PE-ATM & 34 & 50 & 54 & 58 & 61 & 72 & 75 \\
\hline EX-ATM & 20 & 28 & 30 & 35 & 35 & 41 & 55 \\
\hline EX+PE-ATM & 27 & 32 & 39 & 44 & 45 & 56 & 59 \\
\hline PE-TWB & 35 & 40 & 46 & 48 & & 55 & 66 \\
\hline PE-TDWB & 36 & 46 & 51 & 51 & & 53 & 58 \\
\hline
\end{tabular}

PE - Hop pellets; EX - Hop CO2 extract; ATM - Atmospheric boil; TWB - Low-pressure boil; TDWB - Dynamic low-pressure boil; CW - Cold hopped wort; BE - Final beer

nols, the hop raw material is also used at the last dose 20 minutes before the end of boiling. The use of shorter low-pressure boiling (PE-TWB, PE-TDWB) had no significant effect on total polyphenol concentration in the wort.

The concentration of total polyphenols increased throughout the course of the boiling and there was no decrease in the values between hot and cold hopped wort attributable to the elimina-tion of break, tannin-protein complexes. The concentration of total polyphenols in wort and hopped wort correlated with both antioxidant activity (DPPH) and reducing capacity (DCPI) at a probability level of $\mathrm{P}>0.01(\mathrm{n}=25 ; \mathrm{r}=0.90, r=0.84)$. This is somewhat surprising, the DCPI method mainly determines the reducing capacity of melanoidines, sugar reductones and other sub-stances, while the DPPH method primarily reflects the reducing capacity of polyphenols (Kaneda et al., 1995). Both malt and hop polyphenols appear to contribute to the antioxidant properties. The value of total polyphenols represents the whole spectrum of polyphenols, phenolic monocarboxylic acids and flavonoid polyphenols. The method of determination is based on the reduction of ferric ions to ferrous ions.

The decrease of total polyphenols between hopped wort and beer was $30 \%$ of the hopped wort value, slightly lower, $26 \%$ was the decrease in the batch hopped with $100 \%$ hop extract (EX). The concentration of total polyphenols in beer was in relation to the hop materials used, in brews hopped with $100 \%$ pellets and $50 \%$ pellets were $65 \%$ and $30 \%$ higher, respectively, compared to the brew hopped with $100 \%$ of hop extract.

The development of anthocyanogen values during the boiling in the first phase, within 30 minutes of boiling, was similar to that of total polyphenols. In the next course of boiling there was observed a slight decrease in anthocyanogen values (Table 1). For atmospheric boil, there was fur-ther decrease in anthocyanogen concentration between hot and cold hopped wort, probably due to the break formation and precipitation. The decrease was also in the brew without 
hop polyphenols (EX-ATM), both hop and malt polyphenols are involved in the formation of polyphenol protein complexes. In low-pressure boils with higher boiling temperature no decrease of values after hopped wort cooling was observed. The value of anthocyanogens represents a group of polyphenol compounds (catechins, leucoanthocyanidins) with the potential to form tannic-protein complexes, which partially precipitate in the form of hot break during wort boiling. A further elimination of these breaks is during fermentation and maturation of beer, mainly due to a drop in $\mathrm{pH}$ value. The concentration of anthocyanogens in the wort and hopped wort correlated with both antioxidant activity (DPPH) and reducing capacity (DCPI) at a probability level of $\mathrm{P}>0.01$ ( $\mathrm{n}=25 ; \mathrm{r}=0.90, \mathrm{r}=0.84)$.

The concentration of anthocyanogens in beer was in relation to used hop raw materials, in brews hopped with $100 \%$ pellets and $50 \%$ pellets were $58 \%$ and $32 \%$ higher, respectively, com-pared to the brew hopped with hop extract. Both low-pressure boiling technologies (PE-TWB, PE-TDWB) showed significantly lower anthocyanogen loss between hopped wort and beer and these variants resulted in a $43 \%$ higher concentration of anthocyanogens compared to atmospheric hop-ping (PE-ATM) and hence potential for lower colloidal stability of beer.

\section{Flavanols and flavanols-O-glycosides}

Flavanols (catechin and epicatechin) and their glycosides (catechin- $O$-glucoside and epi-catechin- $O$-glucoside) are significant antioxidants (Nowak et al, 2014). These substances showed different dynamics of concentration changes during the brewing process (Figure 1). Catechin and epicatechin are released from the hop matrix within approximately 30 minutes of atmospheric boil of the sweet wort with hops. In the course of the wort boiling and cooling of wort their content decreases slightly. In wort hopped with $100 \%$ pellets, the concentration was roughly twice that of sweet wort, in the wort hopped with $\mathrm{CO}_{2}$ extract the concentration of catechin was 30\% lower than in sweet wort.

The concentration of epicatechin in wort increased threefold when hopping by $100 \%$ pel-lets. Between hopped wort and beer, catechin and epicatechin loss of 45$50 \%$ and $50-55 \%$ re-spectively were determined. During fermentation and maturation of beer, there is a decrease due to $\mathrm{pH}$ drop and formation of tannin-protein complexes, however the concentration of catechin and epicatechin in beer hopped by $100 \%$ and $50 \%$ pellets was approximately three or two times higher than that of hop extract.

The concentration of catechin- $O$-glucoside did not change significantly during wort boil-ing. The average increase between wort and beer was $30 \%$, irrespective of the hopping regime. The concentration of epicatechin-O-glucoside in the wort boiling increased by an average of $75 \%$ and the average beer concentration was in $36 \%$ higher than those in the wort, independent of hopping. Thus, the monoglycosides of flavanols present in beer appear to originate in malt, not in hops. We do not yet have a satisfactory explanation for this phenomenon.

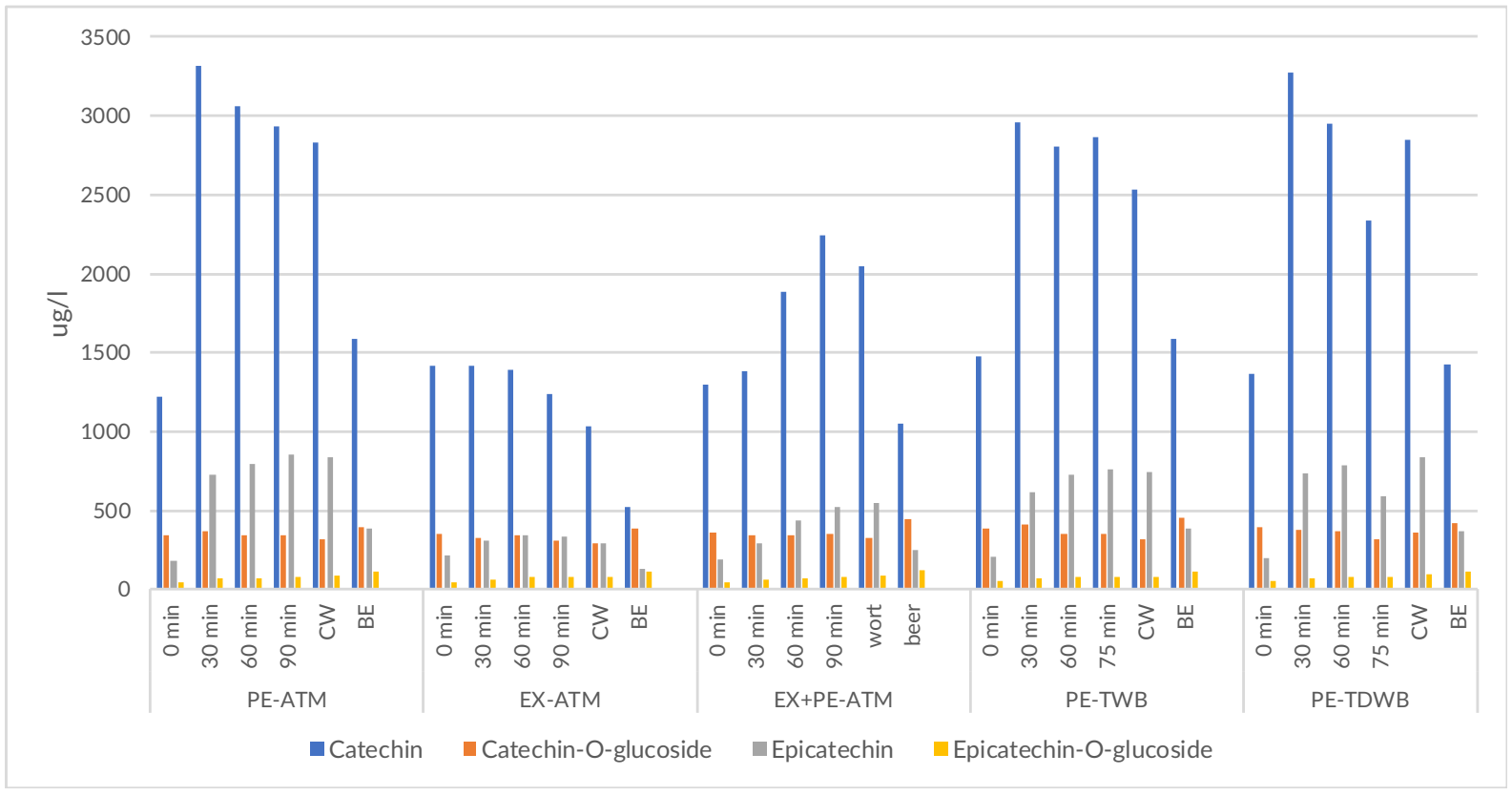

Figure 1 Changes of the concentration of flavanols and their glycosides from sweet wort to beer

PE - Hop pellets; EX - Hop CO extract; ATM - Atmospheric boil; TWB - Low-pressure boil; TDWB - Dynamic low-pressure boil; $C W$ - Cold hopped wort; $B E-$ Final beer; 
The view of the level of the discussed substances in hopped wort and beer in the whole spectrum of tested hopping regimes can be summarized in the sense that the concentration of cate-chin and epicatechin in beer is dominated by hop raw material, i.e. the amount of these polyphe-nols in hops. On the other hand, for the mono $O$-glucosides of catechin and epicatechin, their con-tent wort is significant.

\section{Flavonols and flavonol-O-glycosides}

Flavonols are attributed to greater antioxidant (antiradical) activity than flavanols (cate-chins) (Nowak et al. 2014). Myricetin, quercetin and kaempferol were studied in the flavonol group, some mono- $O$-glycosides of these flavonols, rutin (quercetin- $O$-rutinoside), quercetin- $O$-glucoside, quercetin- $O$-malonylglucoside, myricetin- $O$-glucoside, kaempferol-O-glucoside and multifidol-O-glucoside were analyzed.

Figure 2 shows the results of the analysis of flavonols from wort to beer. It is evident that quercetin and kaempferol are released from hops, while myricetin is derived from wort and its concentration does not change significantly during wort boiling or further fermentation. The result-ing concentration of quercetin and kaempferol in beer was 30-40\% lower than in hopped wort. Most of the flavonols contained in hops are also present in beer.

Similarly, the $O$-glycosides of quercetin and kaempferol are extracted from hops into wort during wort boiling, the major part already within 30 minutes of boiling, and their concentration is in relation to the dose of hops (Figure 3).
Between hopped wort and beer there was a decrease in the concentration of about $20-30 \%$. The exception was rutin, whose concentration in beer was about $50 \%$ higher than the concentration in hopped wort. This phenomenon has also been observed in our other experiments, and this increase is probably caused by the release of rutin by partial hydrolysis of di-glycosides or cleavage of malonyl from the quercetin malonylgycoside by yeast.

From the overall view of the content of the discussed substances in wort and beer in the whole spectrum of tested hopping regimes it can be concluded that the content of flavonols and their glycosides, with the exception of myricetin- $O$-glucoside, is dominated by hop raw material. Beer hopped with hops rich in flavonols and their glycosides contains a relatively high amount of these substances, while beer hopped with $\mathrm{CO}_{2}$ hop extract is very poor in these antioxidants, since these substances are much more polar than flavonols and are not extracted by carbon dioxide. Hop extract contains only negligible amount of polyphenol substances.

\section{Prenylflavonoids}

In the group of prenylflavonoids isoxanthohumol, xanthohumol, 6- and 8-prenylnaringenin were studied. The major prenylflavonoid in hops is xanthohumol, which undergoes isomerization to isoxanthohumol during wort boiling. From the results in Figure 4, the isomerization of xantho-humol during wort boiling is evident, while the content of 6 and 8 prenylnaringenin decreases slightly.

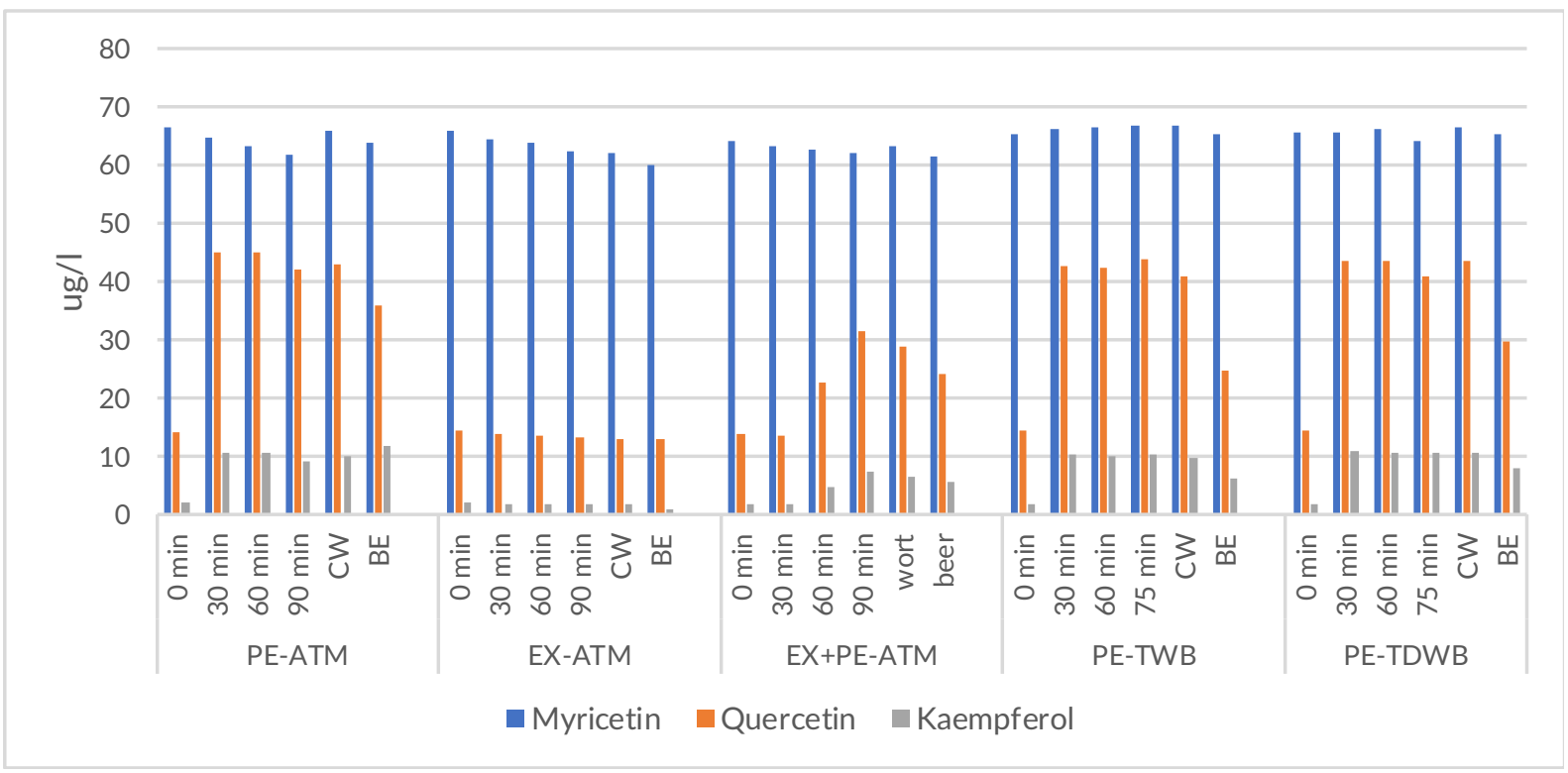

Figure 2 Changes of the flavonols concentration from sweet wort to beer

PE - Hop pellets; EX - Hop CO extract; ATM - Atmospheric boil; TWB - Low-pressure boil; TDWB - Dynamic low-pressure boil; $C W$ - Cold hopped wort; $B E-$ Final beer; 


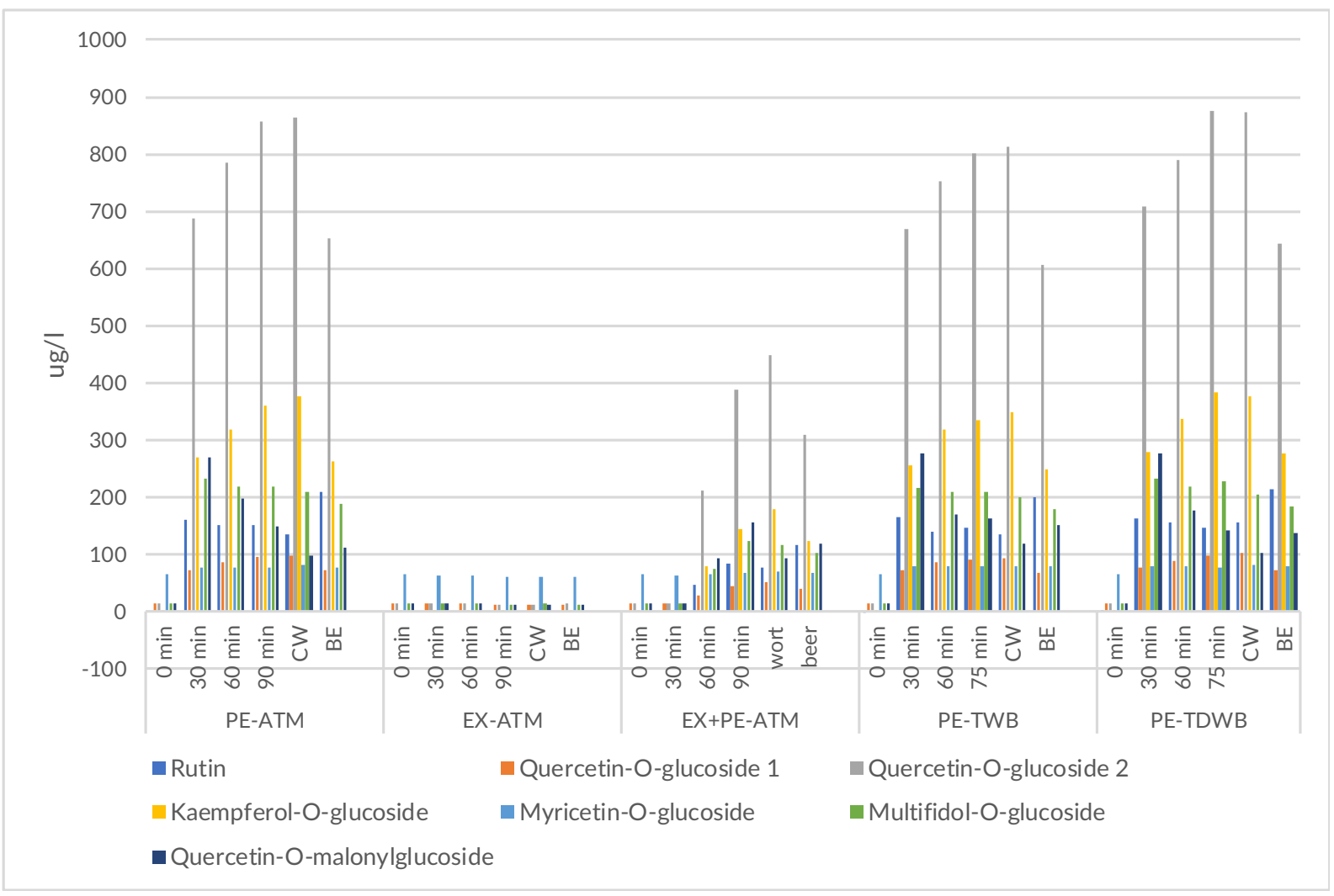

Figure 3 Changes of the concentration of flavonol glycosides from sweet wort to beer

PE - Hop pellets; EX - Hop $\mathrm{CO}_{2}$ extract; ATM - Atmospheric boil; TWB - Low-pressure boil; TDWB - Dynamic low-pressure boil; $\mathrm{CW}$ - Cold hopped wort; $\mathrm{BE}$ - Final beer;

2500

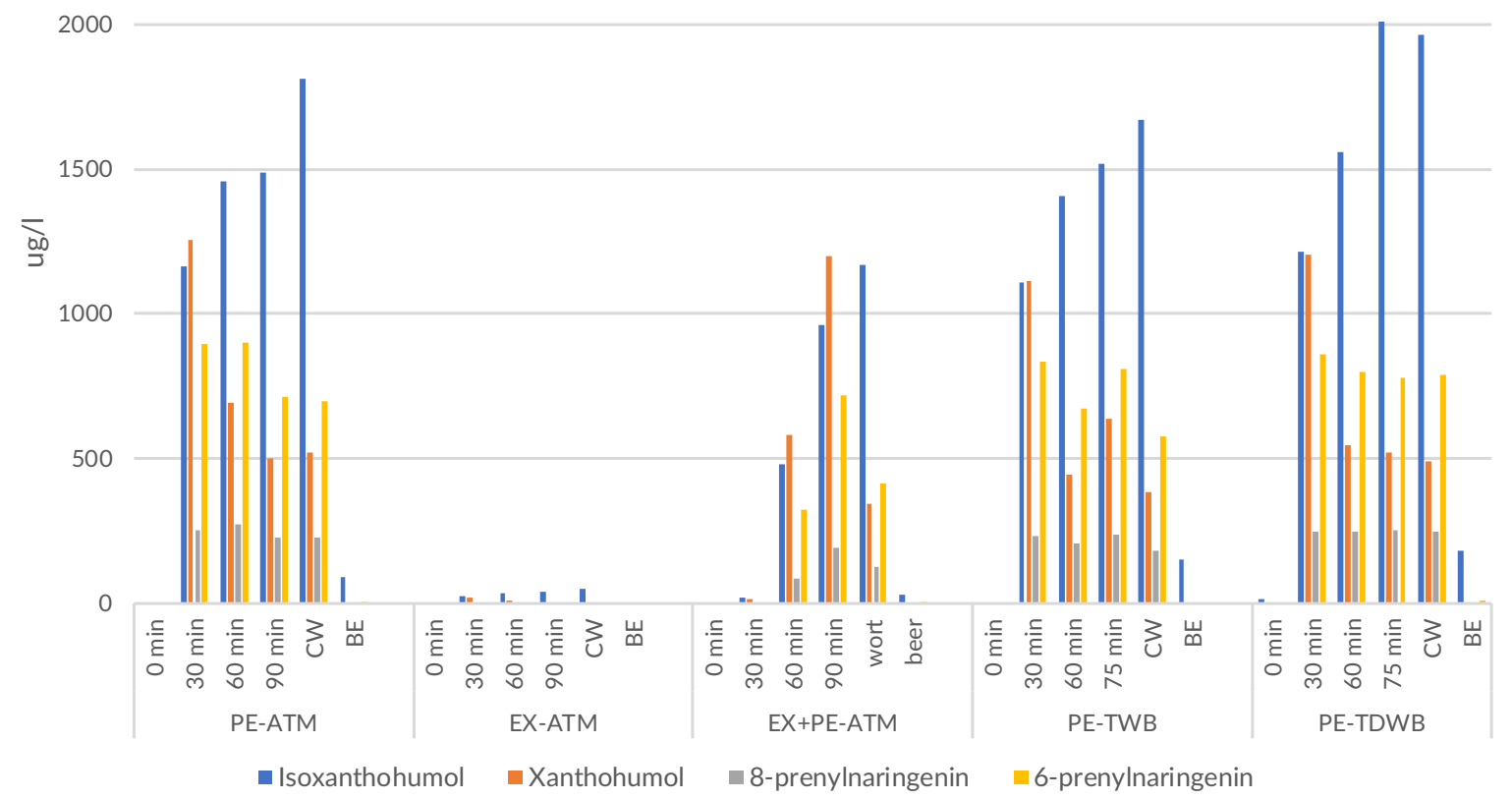

Figure 4 Changes of the prenylflavonoids concentration from sweet wort to beer

PE - Hop pellets; EX - Hop CO extract; ATM - Atmospheric boil; TWB - Low-pressure boil; TDWB - Dynamic low-pressure boil; $\mathrm{CW}$ - Cold hopped wort; $\mathrm{BE}$ - Final beer; 
However, it is also evident that only the major substance, isoxanthohumol, was found to be present in measurable concentration in beer, and the loss from hopped wort to beer was more than $90 \%$. High losses of prenylflavonoids during fermentation are generally known (Stevens and Buhler, 2004). Significant increase of prenylflavonoid content in pale lager beers is possible only in the final stages of beer production.

\section{Acknowledgement}

This study was supported by the Ministry of Agriculture of the Czech Republic within the institutional support MZE-R01918 and by the Technology Agency of the Czech Republic within the Competence Center, project TE02000177.

\section{References}

Analytica EBC, 5th edition, European Brewery Convention, Carl-Hans Verlag, Nürenberg, 1998.

Anastassiades, M., Lehotay, SJ., Stajnbaher, D., Schenck, FJ., (2003): Fast and easy multiresi-due method employing acetonitrile extraction/ partitioning and "dispersive solid-phase extrac-tion" for the determination of pesticide residues in produce. Journal of AOAC International 86(2): 412-431.

Basařová, G. , Šavel, J., Basař, P., Lejsek, K. (2010): Pivovarství. Teorie a praxe výroby piva (Brewing. Theory and Practice of Beer Production). Praha, Vysoká škola chemicko technolog-ická v Praze, 2010. ISBN 978-80-7080-734-7. In Czech.

Biendl, M. (2009): Hops and Health. Technical Quarterly MBAA. 47: 1-7. https://doi.org/10.1094/TQ-46-2-0416-01

Bocquet, L., Sahpaz, S., Hilbert, J. L., Rambaud, C., Rivie're, C. (2018): Humulus lupulus L., a very popular beer ingredient and medicinal plant: overview of its phytochemistry, its bioactivi-ty, and its biotechnology. Phytochemistry Reviews 17: 1047-1090. https://doi.org/10.1007/ s11101-018-9584-y

Bogdanova, K., Kolar, M., Langova, K., Dusek, M., Mikyska, A., Bostikova, V., Bostik, P., Olsovska, J. (2018): Inhibitory effect of hop fractions against Gram-positive multi-resistant bacteria. A pilot study. Biomedical Papers-Olomouc 162 (4): 276-283. DOI: 10.5507/bp.2018.026

Callemien, D., Bennani, M., Counet, C. , Collin, S.(2005): Which polyphenols are involved in aged ber astringency? Assessment by HPLC and time-intensity method. Proc. Eur. Brew. Conv. Congr., Prague, Fachverlag Hans Carl: Nurnberg, CD-ROM, 2005, 809-814.

Callemien, D., Jerkovic, V., Rozenberg, R., Collin, S. (2005a): Hop as an interesting source of resveratrol for brewers: Optimization of the extraction and quantitative study by liquid chro-ma-tography/atmospheric pressure chemical ionization tandem mass spectrometry. Journal of Agri-cultural and Food Chemistry 53: 424-429. https:// doi.org/10.1021/jf040179n

Cermak, P., Olsovska, J., Mikyska, A., Dusek, M., Kadleckova, Z., Vanicek, J., Nyc, O., Sigler, K., Bostikova, V., Bostik, P. Strong antimicrobial activity of xanthohumol and other deriva-tives from hops (Humulus lupulus L.) on gut anaerobic bacteria. APMIS 2017; 125: 1033-1038. https:// doi.org/10.1111/apm.12747
Cermak, P., Paleckova, V., Houska, M., Strohalm, J., Novotna, P., Mikyska, A., Jurkova, M., Sikorova, M. (2015). Inhibitory Effects of Fresh Hops on Helicobacter pylori Strains. Czech Journal of Food Sciences 33 (4): 302-307. https://doi.org/10.17221/261/2014-CJFS

Commission, 2008: Publication of an application pursuant to Article 6(2) of Council Regulati-on (EC) No 510/2006 on the protection of geographical indications and designations of origin for agricultural products and foodstuffs. Official Journal of the European Union C 16-22.

Derdelinckx, G. (2008): Polyphenols in wort and beer : State of art in 2008: Where and why? Cerevisia 33 (4): 174-187.

Dvořáková, M., Guido, L.F., Dostálek, P., Skulílová, Z., Moreira, M.M. , Barros, A.A., (2008): Antioxidant Properties of Free, Soluble Ester and Insoluble-Bound Phenolic Compounds in Dif-ferent Barley Varieties and Corresponding Malts. Journal of the Institute of Brewing 114(1): 27-33. https://doi.org/10.1002/j.2050-0416.2008.tb00302.x

Esslinger, HM. (2009): Handbook of Brewing. Wiley-VCH, Weinheim, Germany. ISBN: 978-3-527-31674-8. DOI: 10.1002/9783527623488.

Hertel, M., Dillenburger, M. (2009): Primary energy savings potential associated with reduc-tion of overall evaporation during wort boiling. Brauwelt International 27(3): 134-139.

Jerkovic, V., Callemien, D., Collin, S. (2005): Determination of stilbenes in hop pellets from dif-ferent cultivars. Journal of Agricultural and Food Chemistry 53: 4202-4206. https://doi.org/10.1021/jf050222m

Kaneda, H., Kobayashi, N., Furusho, S., Sahara, H. , Koshino, S. (1995): Reducing activity and flavor stability of beer. Technical Quarterly MBAA 32(2): 90-94.

Karabín, M., Hudcová, T., Jelínek, L., Dostálek, P. (2016): Biologically Active Compounds from Hops and Prospects for Their Use. Comprehensive Reviews in Food Science and Food Safety Vol. 00, 1-26. https://doi. org/10.1111/1541-4337.12201

Kavalier A.R., Litt, A. Ma, C. Pitra, N. J. Coles, M. C., Kennelly, E. J., Matthews P. D. (2011): Phytochemical and Morphological Characterization of Hop (Humulus lupulus L.) Cones over Five Developmental Stages Using High Performance Liquid Chromatography Coupled to Timeof-Flight Mass Spectrometry, Ultrahigh Performance Liquid Chromatography Photodi-ode Array Detection, and Light Microscopy Techniques. Journal of Agricultural and Food Chemistry 59: 4783-4793. https://doi.org/10.1021/jf1049084

Kondo, K. (2003): Preventive effects of dietary beer on lifestyle-related diseases. Proceedings of the 29th EBC Congress, Dublin. Fachverlag Hans Carl, Nurenberg, 2003. ISBN: 9070143224.

Krofta, K. (2008): Hodnocení kvality chmele. Metodika pro praxi (Evaluation of hops quality. Methodology for practice). Hop Research Institute, Žatec. In Czech ISBN 978-80-86836-84-3.

Maatta-Riihinen, K. R., Kahkonen, M. P., Torronen, A. R., Heinonen, I. M. (2005): Catechins and pro-cyanidins in berries of Vaccinium species and their antioxidant activity. Journal of Agri-cultural and Food Chemistry 53: 8485-8491. https://doi.org/10.1021/jf0504081

McLaughlin, IR., Lederer, C., Shellhammer, TH. (2008): Bitterniss-modifying properties of hop poly-phenols extracted from spent hop material. Journal of American Society of Brewing Chemists 66(3): 174-183. https://doi.org/10.1094/ASBCJ-2008-0619-01

MEBAK (2013) Collection of Brewing Analysis Methods of the Mitteleuropäische Brautech-nische Analysenkommission (MEBAK): Wort, Beer, Beer-based beverages, Nürenberg, Fach-ver-lag Hans Carl, 2013. ISBN 978-3-9805814-7-9.

Mikyška, A., Dušek, M., Slabý, M. (2019): How does fermentation, filtration and stabilization of beer affect polyphenols with health benefits. Kvasny prumysl 65 (4): 120-126. https://doi.org/10.18832/kp2019.65.120

Mikyška, A., Krofta, K., Hašková, D. (2006): Evaluation of Antioxidant Properties of Hop and Hop Products. Kvasny Prumysl 52(7-8): 214225. https://doi.org/10.18832/kp2006020 
Milligan, SR., Kalita, JC., Heyerick, A., Rong, H., De Cooman, L., De Keukeleire, D. (1999): Identification of a potent phytoestrogen in hops (Humulus lupulus L.) and beer. Journal of Clinical Endocrinology and Metabolism, 83: 2249-2252. https://doi.org/10.1210/jcem.84.6.5887

Nowak, R., Olech, M., Nowacka, N. (2014): Plant polyphenols as chemopreventive agents. In: Watson R, Preedy V, Zibadi S, editors. Polyphenols in human health and disease. San Diego: Elsevier Inc. P: 1289-1307. https://doi.org/10.1016/B978-0-12-398456-2.00086-4

Olšovská, J., Kameník, Z., Čejka, P., Jurková, M., Mikyška, A. (2013): Ultra-high-performance liquid chromatography profiling method for chemical screening of proanthocyanidins in Czech hops. Talanta 116: 919-926. https://doi.org/10.1016/j.talanta.2013.07.067

Possemiers, S., Heyerick, A., Robbens, V., De Keukeleire, D., Verstraete, W. (2005): Activa-tion of Proestrogens from Hops by Intestinal Microbiota; Conversion of Isoxanthohumol into 8-Prenylnaringenin. Journal of Agricultural and Food Chemistry. 53: 6281-6288. https://doi. org/10.1021/jf0509714

Possemiers, S., Bolca, S., Grootaert, C., Heyerick, A., Decroos, K., Dhooge, W., De Keuke-leire, D., Rabot, S., Verstraete, W., Van de Wiele, T. (2006): The prenylflavonoid Isoxantho-humol from Hops is Activated into the Potent Phytoestrogen 8-Prenylnaringenin In Vitro and in the Human Intestine. Journal of Nutrition 136(7): 1862-1867. https://doi.org/10.1093/jn/136.7.1862

Rong, H., Zhao, Y., Lazou, K., De Keukeleire, D., Milligan, S.R., Sandra P. (2000): Quantita-tion of 8-Prenylnaringenin, a Novel Phytoestrogen in Hops, Hop Products and Beers by Bench-top HPLC-MS Using Electrospray Ionization. Chromatographia 51(9/10): 545-552. https:// doi.org/10.1007/BF02490811
Stevens, JF. et al. (1999): Fate of Xanthohumol and Related Prenylflavonoids from Hops to Beer. Journal of Agricultural and Food Chemistry 47: 2421-2428. https://doi.org/10.1021/jf990101k

Stevens, J.F., Miranda, C. R., Buhler, D.R. (1998): Chemistry and biochemistry of hop flavo-noids. Journal of American Society of Brewing Chemists 56(4): 136-145. DOI:10.1094/ASBCJ-56-0136

Stevens, JF., Page, JE. (2004): Xanthohumol and related prenylflavonoids from hops and beer: to your good health? Phytochemistry 65: 13171330. https://doi.org/10.1016/j.phytochem.2004.04.025

Tobe, H., et al. (1997): Bone resorption inhibitors from hop extracts. Biosci. Biotech. Biochem. 61(1): 158-159. https://doi.org/10.1271/ bbb. 61.158

Wannenmacher, J., Gastl, M., Becker, T. (2018): Phenolic Substances in Beer: Structural Di-versi-ty, Reactive Potential and Relevance for Brewing Process and Beer Quality. Comprehen-sive Reviews in Food Science and Food Safety Vol. 0, 1-36. https://doi.org/10.1111/15414337.12352

Zanoli, P., Zavatti, M. (2008): Pharmacognostic and pharmacological profile of Humulus lupu-lus L. Journal of Ethnopharmacology 116: 383-396. https://doi.org/10.1016/j.jep.2008.01.011

Zhou, ZH., Zhang, YJ., Xu, M., Yang, CR. , Puerins, A. (2005): Two new 8-C substituted fla-van-3-ols from Pu-er tea. Journal of Agricultural and Food Chemistry 53: 8614-8617. https://doi.org/10.1021/ jf051390h 